\title{
A historicidade do Ensino Superior desde a génese até à actualidade: Suas transformações e impacto no sistema educativo angolano
}

\author{
The historicity of higher education from genesis to today: \\ its transformations and impact on the \\ angolan educational system
}

\section{João Manuel Correia Filho' \\ Taimara Roa Aleaga²}

\section{Resumo}

O aperfeiçoamento do Ensino Superior é um processo contínuo que desde sua génese até os dias atuais, mostrou mudanças substanciais em torno das suas transformações. Deste modo o estudo tem por finalidade comparar as diferentes etapas de desenvolvimento do Ensino Superior em Angola, tendo em conta sua historicidade desde génese até à atualidade, incidindo sobre as suas transformações e impacto no sistema educativo. O artigo é de natureza comparativa, compreensiva e descritiva a partir do estudo bibliográfico e documental. Contudo, considera-se que, é impossível alcançar o desenvolvimento social, sem levar em consideração as Instituições do Ensino Superior, que são fundamentais na preparação, formação e no desenvolvimento do homem.

\footnotetext{
${ }^{1}$ Doutor em Ciências da Educação pela Universidade de Èvora e pela Universidad de la integracion de las Americas. Professor Auxiliar no Instituto Superior de Serviço Social, Investigador do Centro interdisciplinar de História, Culturas e Sociedades da Universidade de Évora. E-mail: jmcf82@yahoo.com.br

2 Mestre em Ciências da Educação Superior, pela Universidad Santiago de Cuba, Professora Auxiliar no Instituto Superior Politécnico Atlântida. E-mail: taimararoa21@gmail.com
} 
Palavras-chave: Historicidade; Ensino Superior; transformação e sistema educativo.

\section{Abstract}

The improvement of Higher Education is a continuous process that, from its genesis to the present day, has shown substantial changes around its transformations. In this way, the study aims to compare the different stages of development of Higher Education in Angola, taking into account its historicity from genesis to the present, focusing on its transformations and impact on the educational system. The article is of a comparative, comprehensive and descriptive nature from the bibliographical and documentary study. However, it is considered that, it is impossible to achieve social development, without taking into account the Higher Education Institutions, which are fundamental in the preparation, training and development of man.

Keywords: Historicity; Higher Education; transformation and educational system.

\section{Introdução}

O Ensino Superior, enquanto sistema educativo, é intencionalmente um espaço permanente de apropriação social e cultural e, como tal, é um espaço de ideias e realização dos seres humanos; logo, como todos os sistemas, não deve ser observado fora do contexto sócio-histórico em que surge e se desenvolve.

Assim a história do Ensino Superior em Angola tem sido objeto de estudos de várias áreas do conhecimento com destaque os de vertentes sociológicas, educacional, históricas, económicas, psicológicas, entre outras. Neste sentido seu surgimento, representa um marco importante na história do país como resultado das constantes revindicações em diversas regiões.

Desta maneira, o Ensino Superior evidencia uma história que tem suportado no tempo os diversos e adversos contextos, cujo percurso está marcado pela conspeção colonial, opressão do sistema ditador, oposição e instabilidade 
decorrente do início da luta armada e das transformações no plano administrativo e governamental, logo após a independência. Ao longo da sua historicidade, tem vivido várias etapas de descentralização e recentralização, as quais não interromperam a sua caminhada.

Nesta perspetiva, 1961 constitui o ano do início da luta armada em Angola, correspondente o período de afirmação nacional, constituindo, assim, um marco importante no surgimento do Ensino Superior em Angola em 1962. Por isso, no contexto angolano pode-se considerar como uma instituição social que em nome de estratégias partidárias e de Estado, fez parte de processos hegemónicos ${ }^{3} q u e$ caracterizam a luta de classes e o confronto político num processo de transformação social.

Por conseguinte no período colonial, este nível de ensino era frequentado pelos filhos da classe burguesa, que dominavam e que não queriam estar distantes dos progenitores. Este período é descrito pela homogeneidade sociocultural com explosão da ciência e da técnica nos meados do século XX, que aumenta a procura desenfreada por técnicos qualificados. Estas instituições eram elitistas, reservadas a um grupo privilegiados, para o desagrado da maioria da população autóctone, instaurando, assim, um conflito entre os grupos e, consequentemente, a luta de libertação assumida pelos movimentos de libertação de Angola.

Portanto, as transformações políticas, sociais e económicas, que o país sofreu desde o início da luta armada até aos dias de hoje, não se podem dissociar do percurso histórico deste subsistema de ensino. Por tal razão, é possível afirmar que o Ensino Superior começa em Angola como instrumento elitista colonial, que estava ao serviço de uma minoria e que, posteriormente, passa a ser agente revolucionário em representação dos interesses da maioria autóctone.

Não obstante a isso, desde os seus primórdios, o Ensino Superior representou intelectualidade e, como tal, não esteve ao alcance de todos, dado o

\footnotetext{
3 Para Apple (1999, p.41) "o conceito de hegemonia refere-se a um processo em que os grupos dominantes de uma determinada sociedade se unem, de modo a formar um bloco social que mantém e garante a sua liderança perante os grupos dominados".
} 
rigor imposto pela sua história e que só os eruditos poderiam ter o que levava a demarcação do território de reputação sócio - cultural e económico diferente do percurso para a busca do conhecimento para a vida profissional, e concomitantemente, para o desenvolvimento de qualquer país.

Sendo assim este artigo tem por objetivo comparar as diferentes etapas de desenvolvimento do Ensino Superior em Angola tendo em conta sua historicidade desde a génese até à atualidade, incidindo sobre as suas transformações e impacto no sistema educativo, utilizando uma abordagem qualitativa, socorrendose da pesquisa bibliográfica e análise documental. Discorreu-se sobre o percurso histórico e desenvolvimento, desde às décadas de 60 e 70 do século XX até a independência e do período pós colonial aos dias de hoje.

Para isso, foi necessário realizar um estudo de natureza qualitativa que se enquadra numa pesquisa analítica, com natureza comparativa, compreensiva e descritiva a partir da análise bibliográfica e documental sobre o Ensino Superior em Angola desde a sua génese até a atualidade.

Para Gil (1999), a pesquisa analítica categoriza-se em histórica, filosófica, revisão e meta-análise. Para este estudo, recorreu-se à categoria histórica, que permitiu a investigação de eventos e realizações passadas com recursos ao método descritivo e analítico. A filosófica ajudou na análise crítica, ao passo que a revisão permitiu avaliar a integração de literatura publicada e, finalmente, a metaanálise consistiu em apresentar resultados prelimitares a partir da quantidade de informações de acordo uma métrica.

Assim, num primeiro momento, fez-se a recolha do acervo bibliográfico, recorrendo a vários autores que abordaram o assunto, como Silva (2004), Burity (2009), Carvalho (2012), Kandingi (2016) e Canga \& Buza (2017), entre outros. Num segundo momento, reuniu-se toda a documentação legislativa como os diferentes decretos, Leis de Base do Sistema de Educação e Ensino em Angola, Anuários Estatísticos do Ensino Superior e outros documentos importantes para a análise que aqui se pretende. Finalmente, para comparar cada etapa, foram estabelecidas três categorias de análise: 
1. Conceção e surgimento da universidade como necessidade de potenciar o nível cultural do país;

2. Extensão e demanda da universidade perante ao número de estudantes

3. Potencialidades educativas e formativas dos processos de ensino, investigação, gestão e extensão.

Relacionado com isso, ao compreender e interpretar a historicidade do Ensino Superior em Angola e Ihe transformar, em função do seu desenvolvimento, significa aprofundar no quê se fez? como se levou a cabo? e entender as distintas etapas do processo. De essa maneira, se construi um conhecimento teórico ou prático e se estabelece a análise comparativa em função de ver se eram essas transformações ou deveriam ser outras às que se esperava no percurso do tempo.

\section{Contextualização histórica do Ensino Superior em Angola}

A periodização histórica do Ensino Superior em Angola é discutida por muitos autores dentre os quais Silva (2004), Carvalho (2012), entre outros, que apresentam etapas muito semelhantes. A partir desta percepção, neste artigo, consideram-se dois períodos no percurso histórico: 0 primeiro é o surgimento e desenvolvimento de 1962-1974 (período colonial) e o segundo é o Ensino Superior pós-independência, de 1975 aos dias atuais, subdividido em quatro fases importantes.

\subsection{Surgimento e desenvolvimento de 1962 - 1975 (período colonial)}

Este período corresponde à fase ditatorial da política dominadora portuguesa, e como consequência, à forte onda de reivindicações dos movimentos de libertação, que culmina com a independência de Angola. Essas reivindicações dos movimentos nacionalistas, a pressão da comunidade internacional para o fim da escravatura, aliada à necessidade da classe burguesa de os seus filhos prosseguirem com os estudos superiores sem que fosse necessário deslocarem-se para a metrópole (Portugal), dá origem ao ensino universitário em Angola. 
O surgimento do ensino universitário em Angola é considerado, também, como uma medida que tinha como finalidade ajudar a suavizar o clima hostil e manter o controlo político administrativo da colónia, devido ao início da luta armada e, concomitantemente, procurar melhorar a situação socioeconómica e cultural.

Assim sendo, $1962^{4}$ corresponde ao marco histórico do surgimento dos Estudos Gerais Universitários (EGU), à luz do Decreto-lei 44530, de 21 de agosto, com a criação de 10 (dez) cursos na chamada "Província Ultramarina de Angola": Médico-cirúrgico; Engenharia Civil, de Minas, Mecânica, Eletrotécnica e QuímicoIndustrial, em Luanda; Agronomia; Silvicultura e Medicina Veterinária na cidade de Nova Lisboa (Huambo) e, finalmente, Ciências Pedagógicas em Sá da Bandeira (Lubango). Importa realçar que, durante a vigência dos Estudos Gerais Universitárias, para alguns cursos no período colonial, os estudantes eram obrigados a viajar a Portugal para poderem concluírem a formação, devido à falta de recursos materiais e humanos.

Deste modo em 1968, por meio do Decreto- lei 48790 de dezembro, o então Estudos Gerais Universitários de Angola passa a chamar-se Universidade de Luanda e, no ano seguinte, inauguram o Hospital Universitário de Luanda para facilitar as práticas para o curso de Medicina (Silva, 2012). Importa referir que, neste período, o Ensino Superior era apenas direcionado aos filhos da classe burguesa, considerados como pessoas da camada superior, devido à cor, posição social, residência e local de nascimento, variáveis que os distinguia das camadas média e baixa, que constituíam a maioria da população às quais fora vetado o direito de ter estudos universitários.

Essa descriminação fez com que o Ensino Superior ficasse confinado às pessoas da zona litoral e dos grandes centros urbanos onde existia a maior concentração dos colonos. Os das zonas suburbanas estavam deserdados desta

\footnotetext{
${ }^{4}$ Independente o ano de 1962 corresponder o ano da criação do ensino universitário em Angola, é importante salientar que a Igreja Católica já tinha criado o Seminário Maior em 1958, onde lecionava-se cursos superiores. Cf. Carvalho (2013).
} 
oportunidade e apenas podiam fazer a formação básica em algumas áreas rurais por meio de escolas católicas e protestantes. Essa descriminação permite mostrar que o Ensino Superior, no período colonial, estava ao serviço de uma agenda com vista extremar a qualidade e a extensão da educação, pois se temia que o sistema colonial ficasse ameaçado pela educação e pelas ideias políticas e sociais.

Assim, a religião e o ensino sempre foram parceiros na concretização da agenda de integração dos africanos no modelo social de dominação no quadro da situação colonial. No entanto, independentemente dos meios utilizados na sua conceção e implementação, a política educativa colonial em África e, particularmente em Angola, visava a "manutenção e o desenvolvimento do sistema colonial" (Silva, 2004, p. 201).

No final deste período, em 1975, houve um desmembramento da Universidade de Luanda, pelo Governo de transição, em três nomeadamente: Universidade de Luanda, Universidade do Huambo e Universidade do Lubango, situadas nas respetivas cidades. Esse período ficou marcado por carências de vária ordem: infraestrutural, falta de pessoal técnico, falta de condições materiais entre outros.

O preconceito e a discriminação eram reflexos do sistema colonial que se tinha incorporado, também, na Educação. Neste sentido, o ensino universitário tinha como finalidade a formação de profissionais competentes, que respondessem às necessidades da população branca (portuguesa), e não da população geral. As políticas educativas nessa altura estavam voltadas ao serviço do bem-estar da elite portuguesa, daí que, segundo Carvalho (2013), no período de vigência do Ensino Superior, entre 1963 e 1974, houve uma evolução de 531 estudantes no primeiro ano de abertura para $4.176^{5}$, em 1974 , ao passo que, posteriormente, o número baixou consideravelmente para 1109 estudantes em 1977, após a descolonização.

\footnotetext{
${ }^{5}$ A maioria destes estudantes era branca. Estima-se que apenas 40 estudantes eram negros e mestiços.
} 


\subsection{Ensino Superior pós a independência de 1975 aos dias atuais}

Para analisar este período, de acordo com as exigências da historicidade, é necessário ter em conta as abordagens de autores como Silva (2004), Carvalho (2012), Burity (2009), Filho (2016), Kandingi (2016), Canga e Buza (2017) entre outros, que tratam de aspetos teóricos e práticos sobre o Ensino Superior em Angola após a independência. Nesta etapa, os angolanos assumem a direção do sistema educacional com mudanças na orientação, tornando-se no centro das prioridades das políticas educacionais e do progresso social do país.

Deste modo, a Universidade de Luanda torna-se numa instituição de abrangência nacional, num momento marcado por muita convulsão, em consequência da queda da ditadura portuguesa e o alcance da independência. Essa liberdade trouxe a necessidade de se tornar o Ensino Superior menos elitista, com vista a formação de quadros que pudessem fazer frente aos desafios de um país livre. Esse processo de mudanças fica marcada por quatro fases que serão descritas nos subtópicos abaixo.

\subsubsection{Fase de afirmação revolucionária (1976 - 1980)}

Com a independência do país era importante uma mudança onde tudo faltava, e a educação não era uma exceção. Era preciso apostar na formação do homem, capaz de interpretar os desafios da jovem nação livre que luta para o desenvolvimento e progresso social. Para Silva (2004), a forma como estava estruturado o Ensino Superior e como e como as atividades eram nele desenvolvidas atendia a uma lógica político-ideológica de uma orientação socialista com pendor marxista-leninista, num sistema monopartidarista com o MPLA (Movimento Popular de Libertação de Angola) no centro da elaboração de todas as políticas públicas.

Neste período, as três universidades, que tinham sido criadas na véspera da independência, pelo Decreto n. ${ }^{0}$ 69/75, de 3 de Maio, que estabeleceu a criação do cargo de diretor-geral do Ensino Superior, no então no governo de transição. Posteriormente, este Decreto foi substituído pelo Decreto n. ${ }^{\circ}$ 60/76, de 19 de 
junho, o qual possibilitou a unificação das três universidades, passando a ser chamada Universidade de Angola, cuja missão consistia na restruturação de todo - sistema de Ensino Superior, afetado pelas transformações imposta pelo momento. Neste mesmo decreto, foi substituída a denominação de diretorgeral por Reitor e, consequentemente, foi criado o Instituto de Investigação Científica de Angola, integrado na Universidade, cujo Reitor passou a ser o Dr. António Agostinho Neto, então Presidente da República Popular de Angola.

Compreende-se, então, que o Ensino Superior, desde a sua génese, se viu inevitavelmente abraçado ao contexto crítico da revolução angolana, cujo foco era a segurança e defesa da integridade nacionais e, sobretudo, a manutenção do poder pelo MPLA. Desta maneira, a guerra civil passaria, desde então, a visar claramente o interesse do MPLA, FNLA (Frente Nacional de Libertação de Angola) e da UNITA (União Nacional para Independência Total de Angola) pela conquista e domínio do poder político de Angola (Neto, 2010).

Portanto, o foco era primeiro combater as "forças imperialistas", no plano militar, e, no plano político, assegurar e manter o poder político, formando o governo. Relativamente ao plano socioeconómico, era prioritário garantir às populações o acesso aos bens de primeira necessidade e aos serviços básicos; mas, a nível cultural, travava-se a luta pela alfabetização do país e pela consequente formação de bases culturais sólidas para a afirmação patriótica do homem.

Nos dois primeiros anos logo após a independência o país praticamente ficou parado em todas as áreas, fruto do êxodo populacional quer de angolanos e portugueses devido à instabilidade. Esta situação fragilizou o setor da educação, transporte, industria, saúde, segurança social, entre outros, que eram assegurados por quadros colonias.

Fruto da situação, o comité central do MPLA, aprovou uma política de desenvolvimento socialista, que vigorou até 1987, mediante a qual atribuía bolsas de estudos para o exterior do país. Muitas dessas bolsas foram financiadas por países da mesma orientação política, destacando-se onde destaca-se a URSS 
(União das Repúblicas Socialistas Soviéticas) e Cuba. Por outro lado, criou-se cooperação com vários países, como Vietnam, Bulgária, entre outros, que enviaram professores que ajudaram a dinamizar o ensino superior no país.

Com o congresso do MPLA, em 1977, criaram-se várias diretrizes como recomendações mediante as quais se estruturava o sistema de ensino em três subsistemas nomeadamente: Subsistema de ensino de base, ensino técnicoprofissional e do ensino superior. Uma das recomendações era o Plano Nacional de Educação para Todos, onde constava a campanha de alfabetização como instrumento de política educativa e numa clara rutura com o sistema de ensino colonial.

\subsubsection{Fase de ajustamento e expansão (1981 - 1991)}

Esta fase foi muito afetada pela guerra civil e pelas políticas económicas de um estado centralizado no poder político, o que criava muitas dificuldades ao desenvolvimento sustentável.

Mas, independentemente da situação política e económica, o Ensino Superior projetava-se para a expansão a nível nacional. Assim sendo, em 1980, o conselho de Ministros, por meio do Decreto n. ${ }^{0}$ 37/80, de 17 de Abril, aprova o primeiro Estatuto orgânico da Universidade de Angola e o Estatuto da carreira Docente por via do Decreto n. ${ }^{\circ} 31 / 80$, de 10 de Abril, instrumentos importantes para o funcionamento do Ensino Superior.

Com a criação destes instrumentos, estabeleceram-se várias parcerias com as indústrias dos petróleos e diamantes, que ajudaram a suprir algumas dificuldades que o orçamento não cobria, permitindo, assim, a afirmação e a expansão do Ensino Superior. Desta forma o protocolo com esses aliados objetivava também criar fontes de financiamento alternativas para colmatar as lacunas deixadas pelo insuficiente orçamento para o setor (Silva, 2004).

De acordo com a primeira avaliação externa, denotou-se que apesar do financiamento das empresas nacionais, não evitou o êxodo do corpo docente e técnicos, a consolidação estrutural e orgânica, a crise institucional (instabilidade 
política, social e económica) e a paralisação da investigação. Esta avaliação negativa levou á criação em 1985, a Universidade Agostinho Neto (UAN) pela Resolução n.ํำ 1/85, de 28 de janeiro, em substituição da Universidade de Angola.

Com a criação da UAN, foi possível dar continuidade à expansão do Ensino Superior, por via do ensino não presencial em regime experimental, em Ciências da Educação, Economia e Direito, com o objetivo de reunir estudantes para as Escolas da Universidade em Luanda, Lubango e Huambo. Funcionavam em regime de núcleos de ensino universitário, em várias províncias, os quais se deslocavam a Luanda de tempo em tempo, para as aulas.

O ensino não presencial constitui-se numa alternativa para expansão do Ensino Superior por outros pontos. Segundo Silva (2004), foi responsabilidade dos governos províncias a criação de condições materiais e humanas. Consequentemente, a UAN responsabilizava-se pelas filosofias e políticas de ensino, ou seja, pela garantia de apoio científico-metodológico, supervisão do seguimento dos programas, das avaliações e disponibilização, a partir das estruturas centrais, e do material didático, bem como dos docentes, periodicamente.

Em 1989, por força do Decreto n. ${ }^{0} 17 / 89$ de 13 de maio e do Estatuto orgânico pelo Decreto n. ${ }^{0}$ 55/89 de 20 de Setembro do Conselho de Ministros, aprova-se um novo Estatuto Orgânico para a UAN. Com isso, permitiu-se a criação de Unidades Orgânicas ${ }^{6}$ em várias províncias do país, distribuindo-se por unidades administrativas, que tinham diferentes designações: Centros, Polos e Núcleos Universitários? ${ }^{7}$.

A distribuição geográfica dos Centros Universitários obedeceu à seguinte organização: Centro Universitário de Luanda (Luanda e Bengo), Centro

\footnotetext{
${ }^{6}$ As Unidades Orgânicas de Ensino e Investigação são as estruturas básicas da Universidade e subordinam-se a um Centro Universitário ou a um Pólo Universitário. As Unidades Orgânicas podem ser Faculdades, Instituto Universitários, Escolas Superiores e Instituto de Investigação Científica (cf. Relatório da UAN, 2002-2004).

7 Os "Centros Universitários" subordinavam-se diretamente à Reitoria da UAN, eram dirigidos por um Vice-reitor ou por um coordenador nomeado pelo Reitor; Os Pólos Universitários eram um embrião de um futuro centro universitário, estando subordinado a um deles, que pode conter Unidades Orgânicas e Núcleos Universitários ainda não autónomos sob o ponto de vista pedagógico e científico (cf. Relatório da UAN, 2002).
} 
Universitário de Cabinda (Cabinda e Zaire), Centro Universitário do Uíge (Uíge, Cuanza-Norte e Malange), Centro Universitário do Huambo (Huambo e Bié), Centro Universitário de Benguela (Benguela e Cuanza-Sul) e Centro Universitário da Huíla (Namibe, Huíla, Cunene e C.-Cubango). Para além dos centros universitários, existiam os pólos universitários, que dependiam hierarquicamente dos centros universitários.

Nos primórdios dos anos 90, registaram-se alterações substanciais no Ensino Superior como consequência das alterações registadas na vida política e socioeconómica do país, como se tem vindo a dizer, na sequência da instauração da democracia multipartidária e da liberalização económica (Neto, 2010). Este facto permitiu, então a criação da primeira universidade privada em Angola, a Universidade Católica de Angola, mediante o Decreto n. ${ }^{\circ}$ 38-A/92, de 7 de agosto, obrigando a UAN a rever os seus estatutos, bem como estimular à aprovação de um Estatuto da Carreira Docente diferente do vigente na altura - Decretos n. ${ }^{0}$ 2/95 e 3/95, de 24 de Março.

\subsubsection{Fase de crise ${ }^{8}$ e confrontação (1992 - 2000)}

A partir de 1992, considera-se a fase marcada com a mudança de regime de monopartidarismo para multipartidarismo com às primeiras eleições em Angola e a adoção da economia de mercado, dando lugar à iniciativa privada. Esta fase é muito conturbada devido à explosão da guerra civil inviabilizando, assim, o desenvolvimento da universidade.

No que tange às questões académicas, essa fase é marcada pelo surgimento do pluralismo académico, pela democratização académica e estrutural, fruto do momento. Deste modo, a gestão da Universidade passou a afastar-se do controlo do partido, começando assim, a chamada democratização interna. As

\footnotetext{
${ }^{8}$ Ainda assim, pode-se considerar que nesta década, apesar dos constrangimentos que a situação de crise impunha, a UAN conseguiu, no plano da formação de docentes, dar um salto substancial na diferenciação do seu corpo docente através da pós-graduação, criando algumas condições para, na década seguinte, projetar os mestrados em várias áreas. $O$ aumento quantitativo e qualitativo do corpo docente nacional constitui, pois, um dos grandes avanços a registar, muito embora, a acção destes docentes, por razões estruturais e conjunturais ainda não se faça sentir como seria expectável.
} 
decisões académicas serem de âmbito e natureza académica, no contexto plural de cultura e corporativismo profissional académico, promovendo a autonomia e a liberdade académico, o que resultou na restruturação dos planos de cursos e dos seus perfis de entrada e de saída.

Essas mudanças são decorrentes do cenário do multipartidarismo, fruto da assinatura dos Acordos de Bicesse (1991), entre o governo do MPLA e a UNITA dos quais resultaram as primeiras eleições, em 1992. Os Acordos de Lusaka (1994) foram base para a instituição de uma administração universitária democrática, na implementação de eleições livres dos seus gestores e autonomização da universidade, à luz do Estatuto Orgânico de 1995.

Consequentemente, em 1997 decorreram às primeiras eleições da UAN, as quais foram interrompidas por força das inúmeras dificuldades que o país atravessava ${ }^{9}$, o que levou, posteriormente, à segunda reforma educativa, com a criação de diversas legislações sobre o Ensino Superior. Foi nesta fase que o sindicato universitário surge, começando a exigir do Estado melhores condições de trabalho, a revisão da tabela salarial, bem como a promoção da carreira. 0 sindicato procurava, também, afastar a gestão da universidade do controlo ideológico do "Partido Estado", buscando assim, a à meritocracia académica, a promoção da dignidade do profissional e a salvaguarda da verdadeira face da ciência.

Neste contexto, torna-se oportuna a luta pela "dignificação da docência", passando a valorizar-se os graus académicos e distinguir o docente como um verdadeiro profissional especialista qualificado. Isso gerou um conflito grande na academia, pelo facto de muitos docentes pós-graduados terem de se sujeitar à avaliação, para ingresso na carreira, por docentes que, em muitos casos, mesmo tendo baixas habilitações, já integravam as categorias de Associado e Titular (Silva, 2004).

\footnotetext{
9 No final da década de 90, a guerra cívil em Angola acentuou e aumentou a dificuldade de circulação de bens e serviços pela capital e as restantes províncias, principalmente no Sul do país, e consequentemente, aumentou a fome e pobreza. Neste período, a Universidade Agostinho Neto era a única no país e foi afetada pelo contexto.
} 
2.2.4. Fase da estabilidade e redimensionamento (2001 -2019)

Nesta fase, é assinalada a segunda Reforma Educativa, em 2001, com a aprovação da Lei n. ${ }^{0}$ 13/0 de 31 de dezembro, a Lei de Base do Sistema de Educação. Consequentemente, foi a aprovação dos Decreto-Lei n. ${ }^{\circ}$ 2/01 de 22 de junho que estabelece as normas gerais reguladoras do subsistema do Ensino Superior e o Decreto n. ${ }^{\circ} 35 / 01$ de 8 de Junho, que regulava o processo de criação, funcionamento, desenvolvimento e extinção das Instituições de Ensino Superior, públicas e privadas.

Este documento sofreu alteração pontual no seu artigo 32.0 através do Decreto n. ${ }^{0}$ 65/04 de 22 de outubro. Por outro lado o Decreto n. ${ }^{0}$ 57/03, aprova o Estatuto Remuneratório do pessoal docente e não docente da Universidade Agostinho Neto e revogava o anterior n. ${ }^{\circ}$ 30/99, de 8 de Outubro e o Decreto Executivo n. ${ }^{0}$ 60/01 de 5 de outubro, que aprova o novo Estatuto orgânico da UAN, convindo a adequá-lo ao Decreto-Lei n. ${ }^{0}$ 2/01 de 22 de junho, e ao Decreto n. ${ }^{\circ} 35 / 01$, de 8 de junho.

Para Neto (2010), com aprovação destes diplomas legais estavam criadas as condições para o surgimento de diferentes instituições privadas do Ensino Superior no país. Tal como foi o caso da Universidade Jean Piaget de Angola, em 2001, o então Instituto Privado de Angola, que em 2007 passou à Universidade Privada de Angola, e a Universidade Lusíada de Angola (2002). Importa referir que a Universidade Católica surge em 1992 por decreto, mas só começa a funcionar no final da década de 90.

Outro marco importante nesta fase é a assinatura dos acordos de Paz, a 4 de abril de 2002, o conhecido Memorando de Entendimento do Luena, que assinala o fim da guerra civil, começando assim, um processo de construção e reconstrução quer das infraestrutura quer do tecido social.

Deste modo, com a paz em Angola permitiu a expansão do Ensino Superior por todas as províncias bem como o incentivo à criação de instituições privadas. Com o aumento das IES, foi necessário a Secretaria de Estado para o Ensino 
Superior (SEES) fizesse uma avaliação das instituições com a finalidade de constatar a qualidade dos serviços prestados. Feita a avaliação verificaram-se vários constrangimentos no domínio da conceção de uma instituição, da gestão do Subsistema do Ensino Superior, do financiamento das instituições, dos currículos e do corpo docente em serviço.

Com a constatação das lacunas, foi implementada em 2006 aprovado pela resolução n. 0 4/07 de 2 de fevereiro, do Conselho de Ministros, as "Linhas Mestras para a melhoria da gestão do subsistema do Ensino Superior". As mesmas compreendiam o plano político, económico, sociocultural e académico de acordo com Despacho n.01/06 de 20 de janeiro - DR n.0 9, 1. a Série, onde estão estampados os desafios e perspetivas do Ensino Superior em Angola (SEES, 2006).

Nesta perspetiva, possibilitou o aumento do número de instituições de Ensino Superior em todo o país, aumentando, assim, o número de estudantes, ao abrigo do Decreto n. ${ }^{0}$ 7/9, de 12 de Maio. Consequentemente, foi possível a reconfiguração da estrutura da UAN, a formação e capacitação de profissionais administrativos, docente, técnico e de apoio. Com o Decreto n. ${ }^{0}$ 7/9, de 12 de Maio a Universidade Agostinho em 2010 ramifica-se originando seis novas Universidades Públicas e o surgimento das sete regiões académicas.

Posteriormente, 2014, as sete regiões académicas tornaram-se oito, ao abrigo do Decreto Presidencial n. ${ }^{\circ}$ 188/14 de 4 de agosto, possibilitando a descentralização do Ensino Superior e a massificação de rede das instituições pelas 18 províncias como se pode observar no Quadro 1: 
Quadro 1: Regiões académicas em Angola

\begin{tabular}{|c|c|c|}
\hline $\begin{array}{c}\text { Regiões } \\
\text { académicas }\end{array}$ & Províncias & Universidades \\
\hline $\mathrm{I}$ & Luanda e Bengo & Agostinho Neto \\
\hline II & Cuanza Sul e Benguela & Katyavala Bwila \\
\hline III & Cabinda e Zaire & 11 de Novembro \\
\hline IV & Lunda Norte, Lunda Sul e Malanje & Lueji-a-Nkonde \\
\hline $\mathrm{V}$ & Huambo, Bié e Moxico & José Eduardo dos Santos \\
\hline VI & Huíla e Namibe & Mandume ya Ndemofayo \\
\hline VII & Uíge, Cuanza e Norte & Kimpa Vita \\
\hline VIII & Cunene e Cuando Cubango & Cuito Cuanavale \\
\hline
\end{tabular}

Fonte: Decreto-Lei n. 5, de 7 de abril de 2009, artigo $7 .^{\circ}$ e o Decreto Presidencial n. ${ }^{\circ}$ 188/14, de 4 de agosto.

Nesta mesma senda, o estado o elaborou em 2009 novos diplomas legais, através do Decreto n. ${ }^{0}$ 90/09, de 15 de dezembro, que estabelece as normas gerais reguladoras do subsistema do Ensino Superior. Desta maneira, incita um agregado de novas regras de administração e gestão, as atribuições dos promotores e dos gestores organizacionais e a avaliação das IES de forma imperativa.

O novo paradigma de gestão universitária ${ }^{10}$ teve como atribuições centrais: a) gerir e materializar as políticas macroeducativas, b) promover, em primeira instância, a massificação do ensino superior. Com efeito, em 2012, o número de instituições de Ensino Superior privadas passou de 13 a 43, na sequência da promulgação do Decreto Presidencial n. ${ }^{\circ}$ 168/12, de 24 de julho.

Fruto desse conjunto de diplomas legais foi possível a elaboração do Plano Nacional de Desenvolvimento 2013/2017, cujo objetivo consistia em criar estímulos capazes de desenvolver um Ensino Superior qualitativo. Com base na adoção de medidas específicas, tornou-se necessária a capacitação das

${ }^{10}$ Decorrente da junção da Secretaria de Estado do Ensino Superior e do Ministério da Ciência e Tecnologia. 
instituições, o melhoramento da qualidade da formação promovida no Ensino Superior, restauração e capacitação das instituições, formação do capital humano existente, gestão material e financeira do Ensino Superior.

Todo esse ambiente legislativo levou à aprovação da nova Lei de Base do Sistema de Educação e Ensino, a Lei n. ${ }^{0} 17 / 16$ de 7 de outubro mediante a qual os principais objetivos gerais do subsistema de Ensino Superior consistem em:

(i) preparar quadros com alto nível de formação científica, técnica, cultural e humana, em diversas especialidades correspondentes a todas as áreas do conhecimento;

(ii) realizar a formação em estreita ligação com a investigação científica orientada para a solução dos problemas locais e nacionais inerentes ao desenvolvimento do país e inserida nos processos de desenvolvimento da ciência, da técnica e da tecnologia;

(iii) promover a extensão universitária, através de ações que contribuam para o desenvolvimento da própria instituição e da comunidade em que está inserida, entre outros.

No final de 2018, foi aprovado o Estatuto da Carreira Docente, ao abrigo do Decreto Presidencial n. ${ }^{0}$ 191/18 de 08 de agosto, em substituição do anterior da Universidade Agostinho, um instrumento que regula a atividade do docente. Toda essa reestruturação do Ensino Superior propiciou o aumento substancial, passando de 12.566 estudantes matriculados e 988 docentes, em 2002, a 261.214 estudantes e 11542 professores. Atualmente Angola conta com 88 (oitenta e oito) Instituições de Ensino Superior, das quais 24 públicas e 64 privadas, uma evolução significativa ao comparar-se com o ano de 2002, que tinha apenas 5 instituições, 1 pública e 4 privadas.

\section{Resultados e Discussão}

Para oferecer uma imagem mais completa acerca do objeto de estudo, a partir dos aspetos essenciais que dinamizam a historicidade do Ensino Superior em Angola se mostra como na primeira etapa (surgimento e desenvolvimento (1962 - 
1975). Tendo em conta as categorias de análises, pode dizer-se que a presença do Ensino Superior, de acordo com as constantes mudanças da sociedade, considera-se um elemento fundamental para compreender a fragilidade do período perante os desafios atuais.

Neste sentido, os trabalhos e documentos científicos analisados têm significado na compreensão da conceção e surgimento do Ensino Superior como necessidade de potenciar o nível cultural do país. Por sua vez, coincide-se que não ocupou um lugar importante até que surge os Estudos Gerais Universitários integrados na Universidade Portuguesa, até 1968, em apenas três cidades da província ultramarina de Angola: Luanda, Huambo e Lubango com a existência de cursos reduzidos.

No entanto, não se mostraram evidências sobre a extensão e demanda do Ensino Superior perante o número de estudantes, mesmo no sentido de trabalhar as potencialidades educativas e formativas dos processos de ensino, investigação, gestão e extensão, o que significa que nenhum referencial teórico estipula a existência destas duas vertentes nessa etapa.

Embora que entre 1968 e 1975, com o surgimento da Universidade de Luanda, se tenha reconhecido a integração do Ministério da Educação e Cultura (MEC), em nenhum caso se trata da existência de como conduzir os processos de ensino, investigação, gestão e extensão, altamente valiosos para alcançar os objetivos da educação neste nível. Por outro lado, são denotadas insuficiências em relação à existência de uma conceção em torno da demanda do Ensino Superior perante o número de estudantes como parte significativa do desenvolvimento social do país.

De igual forma, evidenciou-se assim, um predomínio do caráter hierarquizante, antidemocrático e imobilista do ensino. Não obstante, fez-se uma reconversão dos Institutos Industriais em Escolas Superiores de Tecnologias e criaram-se três núcleos universitários ainda com a gestão centralizada em Luanda.

No que concerne à segunda etapa, que inclui o Ensino Superior após a independência de 1975 aos dias atuais, percebe-se que na fase de afirmação 
revolucionária (1976 - 1980), e até 1985, que abrange parte da fase de ajustamento e expansão (1981 - 1991). Com respeito à primeira categoria corroborou-se que inicia o processo de massificação do Ensino Superior. Surge assim, a primeira explosão escolar e, desta maneira, começam os primeiros passos da extensão e demanda do Ensino Superior diante do aumento do número de estudantes com a criação do ensino não presencial por meio dos centros e pólos universitários.

Isso conduz a compreender a necessidade da contratação de docentes estrangeiros pela insuficiência de quadros angolanos preparados para exercer a direção do processo, manifestando uma excessiva dependência externa. A partir destas interpretações teóricas significativas mostra-se também que ainda não existe uma concretização dos processos de ensino, investigação, gestão e extensão, além de aparecer os primeiros sinais das potencialidades educativas e formativas do processo de ensino, pois é precisamente nesta fase, onde se realiza o primeiro Conselho Universitário.

No que respeita à fase de crise e confrontação (1992 - 2000) além da consolidação estrutural e orgânica da UAN com a implementação de todos os processos (ensino, investigação, gestão e extensão), surge uma crise institucional, que dá lugar numa instabilidade política, económica e social. Cria-se um êxodo do corpo docente e técnicos diferenciados e a sua vez se produz a paralisação do processo investigativo além do surgimento da primeira universidade privada logo da instauração do exercício democrático.

Estas interpretações teóricas inter-relacionadas dão a necessária compreensão de, de uma maneira ou de outra, ao subscrever-se os estudos realizados existe uma deficiência no processo exaustivo de concretização do Ensino Superior. Isso permiteu uma operacionalização teórica baseada na percepção e explicação de cada um dos processos correspondentes às funções nesse nível.

Nesse sentido, o Ensino Superior, era limitado ao estabelecer seu campo de ação, a partir de relações causais, essenciais e julgamentos dirigidos, com o 
objetivo de aperfeiçoar seu campo de ação. Além do desenvolvimento dos processos tendo em conta as suas potencialidades educativas e formativas, a extensão praticamente não existia e no referido a gestão apenas tinha uma mínima manifestação externa.

Por tal motivo, na fase da estabilidade e redimensionamento (2001 -2019), considera-se adequado que um dos aspetos fundamentais do Ensino Superior era contribuir para o desenvolvimento integral de seus estudantes, em função da sociedade. Precisamente desta perspetiva, promove-se o redimensionamento da UAN e com a regionalização do Ensino Superior criaram- se mais de sete universidades públicas. Além disso, foi inaugurado o primeiro campus universitário e transformou-se o INAAES (Instituto Nacional de Avaliação, Acreditação de estudos do Ensino Superior) em Instituto Nacional de Avaliação, Acreditação e Reconhecimento de Estudos do Ensino Superior (INAARES).

Considera-se nesta década, apesar dos constrangimentos que a situação de crise impunha, a UAN conseguiu, no plano da formação de docentes, dar um salto substancial na diferenciação do corpo docente através dos cursos de pósgraduação, criando algumas condições para projetar os mestrados e doutoramentos em várias áreas. O aumento quantitativo e qualitativo do corpo docente nacional constituiu, pois, um dos grandes avanços a registar, muito embora, a ação deles, por razões estruturais e conjunturais, ainda não se faça sentir como seria expetável.

É evidente que, apesar das transformações e impactos do sistema educativo angolano que existem até ao momento nas instituições, sejam privadas ou públicas, em decorrência dos diversos mecanismos utilizados para seu desenvolvimento, ainda existem limitações quanto aos processos principais, especificamente os de investigação, extensão e gestão.

Relacionado com o exposto, assume-se que é necessário enfrentar os desafios que conduzam a alcançar os objetivos e finalidades da educação e instrução dos estudantes no Ensino Superior. Deste modo deve-se levar em conta que o conhecimento consegue-se desenvolver a partir de estudos que o Ensino 
Superior oferece, projetando no seu trabalho sistemático, planificado, flexível através dos seus processos e suas ações; portanto, não é uma transmissão passiva, mas sim criativa.

\section{Considerações finais}

A história do Ensino Superior esteve sempre associada aos contextos sociais, históricos e políticos do país que possibilitou as transformações significativas no sistema educativo. Note-se que as diferentes etapas foram caraterizadas por avanços e recuos, mas que, nos últimos dez anos, há um avanço considerável do Ensino Superior, com a expansão acelerada das instituições quer públicas, quer privadas. Mas apesar disso, não deixou de sobressair distintivamente entre as suas congéneres, facto que resulta do capital de experiências no impacto do sistema educativo acumulado ao longo do seu percurso existencial, bem como da concentração de recursos diferenciados, mormente humanos.

O estudo permitiu mostrar que o primeiro período, o do surgimento e desenvolvimento, está associado à conceção e surgimento do Ensino Superior como necessidade de potenciar o desenvolvimento da ciência e da técnica. Desta forma, a potência colonizadora sentiu a necessidade de melhorar o nível cultural e profissional da sociedade, mas, infelizmente, estava direcionado apenas para a classe elitista. O governo colonial receava que um significativo investimento no Ensino Superior para todos poderia excitar a crítica social e a insegurança de políticas colocando em causa a sua administração.

Um dos pontos comuns observados em todos os períodos foi a tendência de expansão do Ensino Superior, embora com estratégias diferentes, onde no período colonial, o Ensino Superior era destinado à classe burguesa, ao passo que, no período pós independência, era para todos. Os constrangimentos históricos e sociais impossibilitaram o desenvolvimento da segunda e a terceira categorias no período colonial. 
Relativamente à potencialidade educativa e formativa dos processos de ensino, investigação, gestão e extensão, só foi possível observar a partir da terceira fase no período de 1992 a 2000, mas ainda de forma tímida dando maior realce ao ensino, investigação e à estruturação da gestação com a criação de alguns instrumentos. Quanto a extensão os documentos analisados não mostram nenhum indicador que permite aferir.

Esta categoria observou-se com maior relevo na quarta fase, de 2002 a 2019, onde se notou um crescimento substancial do Ensino Superior. Nesta fase, por meio da documentação consultada, compreende-se que a indissociabilidade entre ensino, investigação, gestão e extensão não se reduz apenas a uma contenda conceitual ou legislativa, mas, principalmente, paradigmática, epistemológica e político-pedagógica.

Em síntese, a história do Ensino Superior em Angola comportou a era da universidade colonial, que diz respeito à instituida pelo colonizador, a era do Ensino Superior no pós-independência, que visava a afirmação da soberania nacional através da nacionalização, com vista a autodeterminação do campo académico; e, finalmente, a era das universidades de desenvolvimento, que materializam os pressupostos e os fins estratégicos para o desenvolvimento das transformações do sistema educativo de angolano.

\section{Referências bibliográficas}

Angola. Decreto executivo n.0 38-A/92, de 7 de agosto de 1992, criação a Universidade Católica de Angola (UCA).

Angola. Decreto Executivo n. ${ }^{0}$ 60/01, de 5 de Outubro de 2001 - publicado no Diário da República I Série - n.o 46 - Ministério da Educação e Cultura - aprova o Estatuto Orgânico da Universidade Agostinho Neto.

Angola. Decreto executivo no 26/11 de 23 de Fevereiro de 2011. Publicado no Diário da República I Série, No 77 - estabelece as normas gerais reguladoras do subsistema do ensino superior. 
Angola. Decreto n. ${ }^{0}$ 17/89, de 13 de Maio de 1989 - publicado no Diário da República I Série - n.o 18 - aprova o Estatuto Orgânico da Universidade Agostinho Neto.

Angola. Decreto n.0 3/95, de 24 de Março de 1995 - publicado no Diário da República I Série - n. ${ }^{\circ} 12$ - aprova o Estatuto da Carreira Docente Universitária. Angola. Decreto n. ${ }^{0}$ 31/80, de 10 de Abril de 1980 - publicado no Diário da República. I Série - no 85 - aprova o Estatuto da Carreira Docente Universitária. Angola. Decreto n. ${ }^{0}$ 35/01, de 8 de Junho de 2001 - publicado no Diário da República I Série - aprova o estatuto das instituições do ensino superior.

Angola. Decreto n.0 7/09, de 12 de Maio de 2009 - publicado no Diário da República. I Série - n.0 87 - estabelece a reorganização da rede de instituições de Ensino Superior públicas, a criação de novas instituições de Ensino Superior e o redimensionamento da Universidade Agostinho Neto (UAN).

Angola. Decreto no 11/05 de 11 de Agosto de 2005. Publicado no Diário da República I Série, No 87 - estabelece as normas gerais reguladoras do subsistema do ensino superior. (cf. 2a. Conferência do FORGES, 2012, p.7-8). Angola. Decreto No 57/03, de 5 de Setembro de 2003 - publicado no Diário da República. I Série no 70 - aprova o estatuto remuneratório do pessoal docente e não docente da Universidade Agostinho Neto.

Angola. Decreto no 90/09, de 15 de Dezembro de 2009. Publicado no Diário da República I Série, No 87 - estabelece as normas gerais reguladoras do subsistema do ensino superior.

Angola. Decreto Presidencial n. ${ }^{0} 188 / 14$ de 4 de Agosto de 2014, Estatuto Orgânico da Universidade Cuito Cuanavale. I Série-N. ${ }^{0143}$

Angola. Decreto Presidencial n. ${ }^{0}$ 252/11, de 26 de Setembro de 2011 - publicado no Diário da República. I Série - n. 185 - aprova o Estatuto Orgânico do Instituto Nacional de Avaliação e Acreditação do Ensino Superior.

Angola. Decreto Presidencial no $168 / 12$ de 24 de Julho de 2012. Publicado no Diário da República II Série, No 97 - estabelece as normas gerais reguladoras do subsistema do ensino superior. 
Angola. Decreto Presidencial No 191/18, de 08 de Agosto de 2018 - publicado no Diário da República. I Série no 118 - aprova o Estatuto da Carreira Docente do Ensino Superior.

Angola. Decreto-lei n. 5, de 7 de Abril de 2009. Publicado no Diário da República I Série, No 73 - Aprova o Estatuto orgânico do Ministério do Ensino Superior e da Ciência e Tecnologia.

Angola. Decreto-Lei n. ${ }^{0}$ 2/01, de 22 de Junho de 2001 - publicado no Diário da República. I Série - n.0 28 - estabelece as normas gerais reguladoras do subsistema do Ensino Superior.

Angola. Decreto-Lei n. ${ }^{0}$ 5/07, de 5 de Abril de 2007- publicado no Diário da República. I Série - n.o 42. Conselho de Ministros - aprova o Estatuto Orgânico da Secretaria de Estado para o Ensino Superior.

Angola. Decreto-Lei n.0 5/09, de 7 de Abril de 2009 - publicado no Diário da República. I Série - n.0 64 - cria as Regiões Académicas que delimitam o âmbito territorial de atuação e expansão das instituições de ensino superior.

Angola. Decreto-lei no 44530, de 21 de agosto de 1962, da Administração Colonial Portuguesa - Criação dos Estudos Gerais Universitários.

Angola. Decreto-lei no 48790, de 23 de dezembro de 1968 - Alteração da denominação de Estudos Gerais Universitários para Universidade de Luanda.

Angola. Lei n. ${ }^{0}$ 13/01, de 31 de Dezembro de 2001 - publicada no Diário da República I Série - n.0 65 - Lei de Bases do Sistema de Educação.

Angola. Lei no 17/16, de 7 de Outubro de 2016. Diário da República no 170. I Série - Lei de Bases do Sistema de Educação.

Angola. Portaria n. ${ }^{0}$ 77-A/76 de 26 de novembro de 1976 - publicado no Diário da República. I Série - n.o 279, - põe em vigor o Diploma Orgânico da Universidade de Angola.

Angola. Resolução n. ${ }^{0}$ 1/85, de 28 de janeiro de 1985 - publicado no Diário da República. I Série - n.o 9 - altera a designação da Universidade de Angola para «Universidade Agostinho Neto». 
Canga, J. L. e Buza, A. G. (2017). Gestão do Ensino Superior em Angola os desafios endógenos e exógenos. Conferência do Forum da Gestão do Ensino Superior nos países e Regióes de Língua Portuguesa (pp. 51-62). Universidade de Coimbra: Forges 5.

Carvalho, P. (2012). Evolução e crescimento do ensino superior em Angola. Revista Angolana de Sociologia, 8, 51-68.

Carvalho, P. (2013). Evolução e Crescimento do Ensino Superior em Angola. Lisboa: Centro de Estudos Africanos. Instituto Universitário de Lisboa (ISCTEIUL).

Burity, S. (2009). Repensar a Profissionalização em Ciências da Educação. Luanda: ESDA-JAM.

Filho, J. C. O. (2019). O perfil do docente universitário em Angola no século XXI, suas perspetivas e desafios: Um estudo exploratório em torno de conceções e de práticas (Tese de Doutoramento). Évora: Instituto de Investigação e Formação Avançada Universidade de Évora.

Filho, J. C. (2016). Metodologias didáticas utilizadas no ensino superior em Angola: Caso do Instituto Superior Metropolitano de Angola (Tese de Doutoramento). Assuncion: Universidad Americana.

Filho, J. M., Aleaga, T. R. e Sacomboio, F. D. (2020). A massificação do ensino superior como política pública educacional e suas implicações em Angola. Revista Brasileira de Política e Administração da Educação, 36 (2), n. 2, 750767.

Gil, A. C. (1999). Métodos e Técnicas de Pesquisa Social. São Paulo: Atlas.

Kandingi, A. (2016). A expansão do ensino superior em angola. Um estudo sobre impacte das instituições de ensino superior privado (Tese de Doutoramento). Lisboa: Universidade Nova de Lisboa.

Lakatos, E. e Andrade, M. (1997). Metodologia Científica: Ciência e Conhecimento Científico. São Paulo: Atlas.

Neto, T. D. (2010). História da Educação e Cultura de Angola Grupos nativos colonização e Independência. Angola: Zaina. 
SEES (2005). Linhas Mestras para a melhoria de gestão do Subsistema do Ensino Superior. Luanda: Secretaria de Estado Para o Ensino Superior, CDI/SEES.

SEES (2006). Plano de Implementação das Linhas Mestras para a melhoria de gestão do Subsistema do Ensino Superior. Luanda: Secretaria de Estado Para o Ensino Superior, CDI/SEES.

Silva, A. E (2004). O Burocratico e o Politico na Administracao Universitaria. Comunidades e rupturas na gestao dos recursos humanos docentes na Universidade Agostinho Neto (Angola) (Tese de Doutoramento). Braga: Instituto de Educação e Psicologia \Universidade de Minho

Silva, A. E. (2009). Autonomina e Liberdade Académicas na UAN: Realidade ou utopia? Revista Angolana de Sociologia, 3, 9-29.

Silva, A. E. (2011). Universidade publica angolana e gestão académica entre a burocracia e a política. In T. Manuel e M. Mendes, M., Empreendimentos e Consultoria (pp. 35-59). Luanda: UAN.

Silva, A. E. (2012). Universidade Agostinho Neto: Quo Vadis? Luanda: Editorial Kilombelombe..

U.A.N. (2008). Relatório Anual. Luanda: Universidade Agostino Neto.

Recebido em: 31 de agosto de 2020

Aceito em: 27 de setembro de 2020 